\title{
Postero-lateral subluxation of the superior tibio-fibular joint
}

\author{
N.R. Gillham, FRCS and R.N. Villar, FRCS \\ Department of Orthopaedics, Addenbrooke's Hospital, Cambridge
}

Foot drop resulting from subluxation of the superior tibiofibular joint is described in a female dancer. Spontaneous resolution of the nerve injury occurred over two months with no residual joint instability. Expectant management is recommended for this injury. The potential for this unusual injury, in a wide variety of sports, is pointed out.

Keywords: Superior tibio-fibular joint, subluxation, dancer

A 22 year old professional ballet student landed awkwardly on a minimally flexed left knee whilst dancing. The left knee subsequently became swollen and she was unable to bear weight due to pain. Within hours she developed a foot drop and loss of sensibility in the lateral border of the left leg and foot, She sought the advice of her general practitioner who recommended rest. The swelling resolved over three to four days and the left foot drop recovered over a period of one month. Sensibility in the foot remained altered.

She presented to an orthopaedic clinic two months after the injury because of persistent pain. She had a full range of movement of the left knee and ankle. There was tenderness over the head of the fibula which felt more prominent, but there was no abnormal movement of the fibula. The left foot had normal motor function but there was altered light touch sensibility in the lateral border of the foot.

Radiographs revealed a postero-lateral subluxation of the proximal fibula at the superior tibio-fibular joint (Figures 1 and 2).

Traumatic dislocations or subluxations of the proximal tibio-fibular joint are rare. Nelaton first described a case in 1874 . Since then only around a hundred cases have been reported in the literature. The diagnosis is easily missed ${ }^{1}$.

Ogden classified injuries of this joint into four types: (i) subluxation (ii) antero-lateral dislocation (iii) postero-medial dislocation (iv) superior dislocation ${ }^{2}$. The antero-lateral dislocation occurs most frequently.

Associated damage to the common peroneal nerve is a recognised complication of superior tibio-fibular joint dislocation. It has been recorded most commonly with antero-lateral dislocations ${ }^{3}$, but also with postero-medial and superior dislocations, as well as in cases of chronic instability ${ }^{2}$.

Address for correspondence: Mr N.R. Gillham, Addenbrooke's Hospital, Hills Road, Cambridge CB2 2QQ

(C) 1989 Butterworth \& Co (Publishers) Ltd 0306-3674/89/030195-02 \$03.00
The prognosis for a common peroneal nerve palsy associated with posterior displacement is good, although it may require operation ${ }^{4}$. Common peroneal nerve injury may also be associated with injury to the lateral collateral ligament of the knee, and in these cases has a poor prognosis ${ }^{5}$.

Traumatic dislocation of the head of the fibula has been reported after a variety of sports. It has been recorded following a fall from a height such as parachuting $^{6}$ or in contact sports such as judo, rugby or soccer ${ }^{7}$. It has also been recorded following skiing or gymnastic injury.

The mechanisms reported have been twisting athletic injuries in which the patient lands with a flexed knee, usually to at least 80 degrees, before dislocation can occur. This was not the case in our patient whose knee was barely flexed at all.

In the case presented here, injury to the superior tibio-fibular joint occurred with a minor fall with the knee almost fully extended. This resulted in a subluxation rather than a dislocation. Damage to the common peroneal nerve is therefore surprising in view of the lesser extent of injury.

Diagnosis was missed for two months. Despite this, recovery gradually took place. Reduction of the subluxation was not necessary. We would thus advocate expectant management for this injury. Awareness of this possible injury in a number of sports would make missing this unusual injury less likely.

\section{References}

1 Falkenberg, P. and Nygaard, H. Isolated anterior dislocation of the proximal tibio-fibular joint J Bone Joint Surg $1983,65 B(3), 310$

2 Ogden, J.A. Subluxation and dislocation of the proximal tibiofibular joint J Bone Joint Surg 1974, 56A(1), 145

3 Turco, V.J. and Spinell, A.J. Antero-lateral dislocation of the head of the fibula in sports Am J Sports Med 1985, 13(4), 209

4 Dennis, J.B. and Rutledge, B.A. Bilateral recurrent dislocation of the superior tibio-fibular joint with peroneal nerve palsy J Bone Joint Surg 1958, 40A(5), 1146

5 Watson Jones. In Fractures and joint injuries (Ed. Wilson, J.N.) E. and S. Livingstone Ltd 1982

6 Lord, C.D. and Coutts, J.W. A study of typical parachuting injuries occurring in two hundred and fifty thousand jumps at the parachute school J Bone Joint Surg 1944, 26A(3), 547

7 Thomason, P.A. and Linson, M.A. Isolated dislocation of the proximal tibio-fibular joint J Trauma 1986, 26(2), 192 

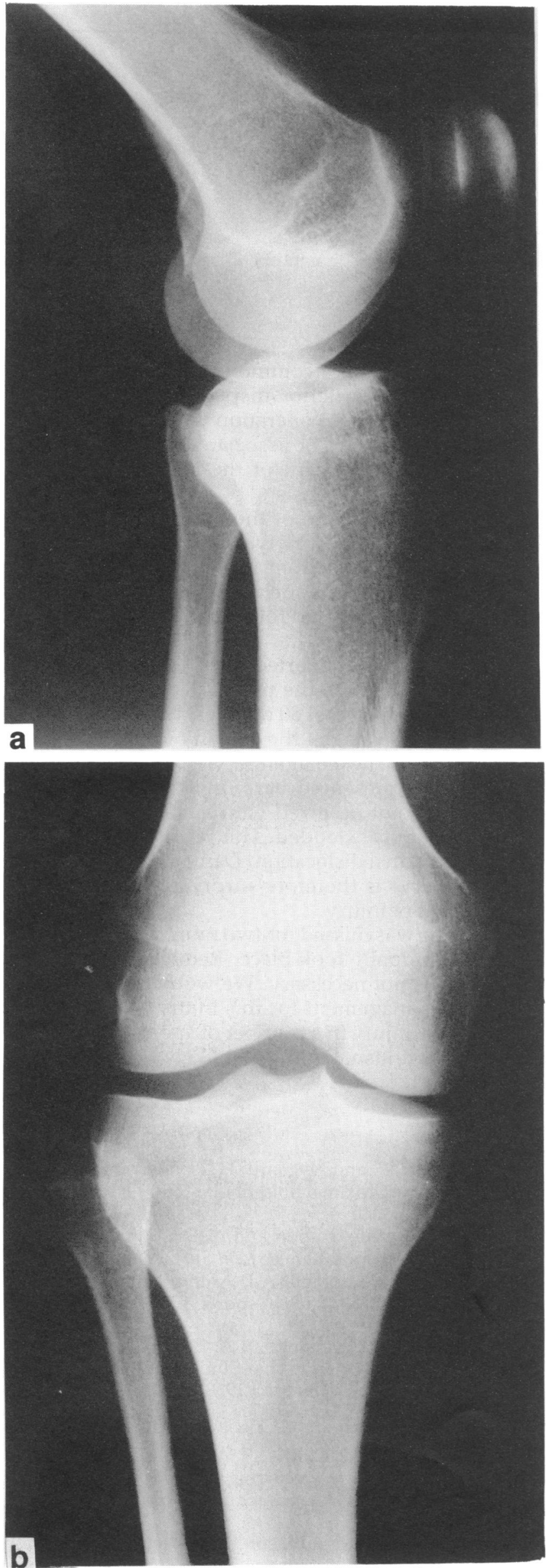

Figure $1 \mathrm{a}$ and $\mathrm{b}$. The normal uninjured right knee
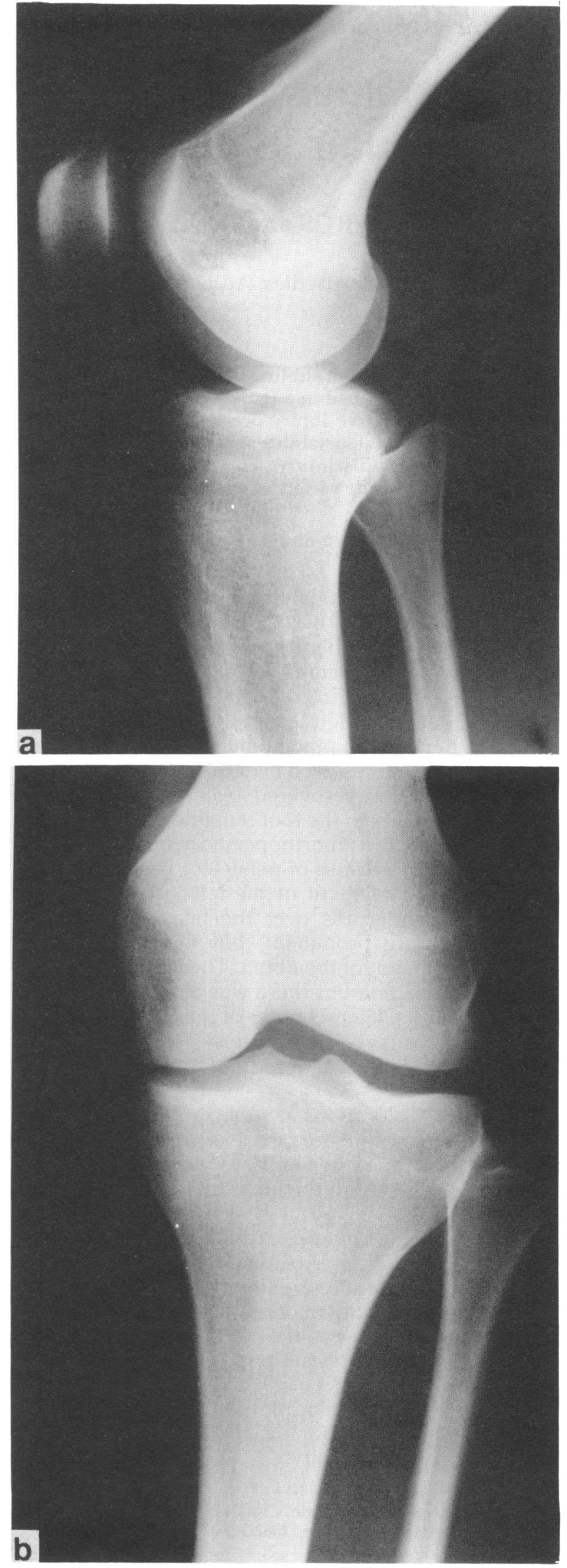

Figure 2 a and b. Left knee, demonstrating subluxation of the superior tibio-fibular joint 